\title{
A Survey on Web Service Selection and Ranking Methods
}

\author{
Ronak R Kayastha \\ Research Scholar, CSE Department \\ Parul Institute of Engineering and Technology \\ Vadodara, Gujarat, India
}

\author{
Jwalant Baria \\ Assistant Professor, CSE Department \\ Parul Institute of Engineering and Technology \\ Vadodara, Gujarat, India
}

\begin{abstract}
Now day's web service is getting more and more popularity because of its characteristic like loosely coupled, composable, reusable, platform independent etc... Due to this popularity web services are developed with similar functionality. When user search web service in directory, Directory retrieve many web service with similar functionality. Web service recommendation only base on functionality matching is not good approach. In this situation web services are recommend base on QoS. QoS is considering as secondary approach for service selection. QoS consider different Non function properties of web service like response time, reliability, availability etc... This paper conduct a survey on different web service Selection and Ranking process.
\end{abstract}

\section{Keywords}

QoS, Web Service, Web Service Selection, Web Service Ranking.

\section{INTRODUCTION}

SOA is an architectural style for building enterprise solutions based on services. SOA is concerned with the independent construction of business-aligned services that can be combined into meaningful, higher-level business processes and solutions within the context of the enterprise [9]. SOA define Web services and related components and the IT infrastructure that allows applications to be composed from services written in different languages and running on different platforms.

"Web Service is a distributed application designed to support interoperable Machine to Machine interaction over internet." A Web Service publishes information on the Internet or an intranet. Like a web page, a Web Service is accessed through a Uniform Resource Locator (URL). Web service are based on open protocols and standards such as SOAP,WSDL, WSBPEL, WS-Choreography, WS-Transaction, WS-Security, WS-Addressing, and many more developed by standardization organizations such as W3C and OASIS. Web service can be publish, discover and bind. Web Service registry is a logically centralized directory of services. A Web service provider needs to create a Web service and then publishes the Web service information on the Web service registry. Web service client uses the Web service registry to find out the Web service information. Finally, the Web service client invokes the Web service available at the Web service provider.

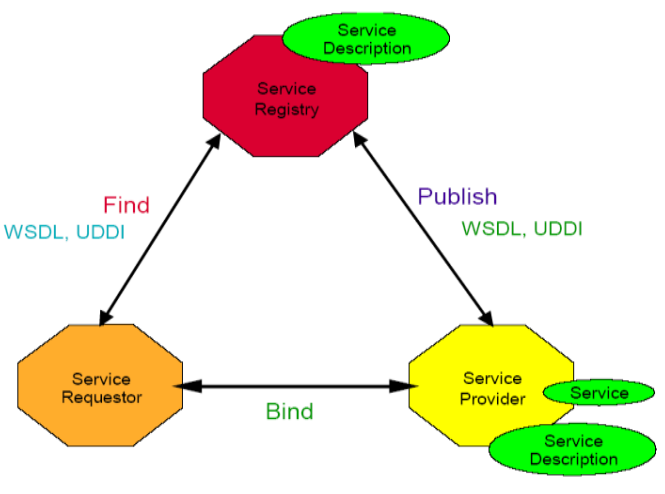

Rest of the paper is organized as follows: Section 2 describes the Problem statement. Section 3 discusses the web service selection. Section 4 discusses web service QoS Computation. Section 5 discusses web service ranking. Section 6 discusses web service selection and ranking approaches. Section 7 concludes with a summary and future scope.

\section{PROBLEM STATEMENT}

In this Internet world web service is getting more and more popular technology today. Due to this popularity many web services are developed with similar functionality. When user searches service into UDDI directory, directory retrieve several web service with similar functionality. The problem become more complicated when discovery process return several web service with similar functionality. User has no way to select suitable web service. In this situation quality of web service is consider as secondary approach for service selection. Furthermore Service provider required high quality service for service composition because one service with low quality can affect quality of overall web service. So, web service recommendation with non-functional quality become very important.

\section{WEB SERVICE SELECTION}

Web services are select base on functionality matching. Web Service functionality is the operation that service can perform. Web service recommendation system search web service by matching functionality and user requirement. Service functionality Matching process is based on keyword or semantic matching. Key word base approach find service using keyword matching like weather service, sms service etc. Semantic base approach focuses on the relation between words, phrases, signs, and symbols, and what they stand for.

\section{QOS COMPUTATION}

QoS is considering most important criteria for service selection. Functional properties of service describe what service can do and non-function properties describe how service can do. This non- functional property of web service is quality and it help user to select web service. QoS is 
combination of different non-functional parameter. Fig 2 show classification of some non-functional parameter used in [4] [10] [5] [3].

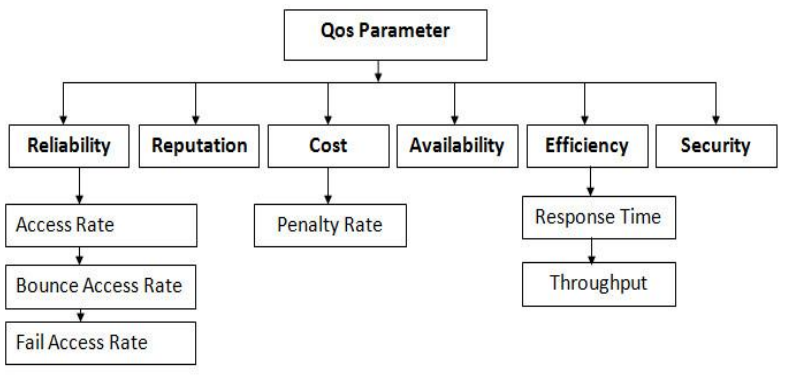

Fig. 2. Non-functional parameter classification.

For service selection, web service QoS calculation and ranking is required. This QoS calculation is perform by trusted third party like broker used in [1]. Broker monitor web service and calculate quality of service and store QoS data into database. Some Parameter explanation and calculation are explained below.

Reliability: Ratio of the number of error messages to total messages.

$$
\text { Reliability }=\frac{\text { Total Message }}{\text { Error message }}
$$

Availability: Availability is ration of successful invocations/total invocations.

$$
\text { Availability }=\frac{\text { Successful invocation }}{\text { Total invocation }}
$$

Cost: Amount of money that user have to pay for consuming web service.

Security: It is degree of protection that service includes.

Throughput: It is the total Number of bits (invocation) for a given period of time.

$$
\text { Throughput }=\text { bit } / \mathrm{sec}
$$

Reputation: Average calculation of different user opinion for particular services.

Response Time: Response time is time taken to send a request and receive a response.

\section{Response Time $=$ Request time + Server time + response t $i$}

Penalty Rate: Extra usage rate of service.

\section{WEB SERVICE RANKING}

In Ranking Process functionally matched services are rank base on QoS aggregation score, User preference, Reputation, service Location and Parameter weighting.

User preference: All users have different and specific requirement for non-functional properties. For example one need ranked base on reliability, another want ranking based on cost. So the selection mechanism should enable the users to sort the services by individual preferences and also highlight the relation between the various properties.

QoS Aggregation score: After the individual properties have been tested and evaluated, they need to be combined to get the aggregate score for the web service. For this purpose an appropriate aggregation method is used to calculate quality score of service.

Reputation: Reputation is rate or recommendation given by end user to web service. Reputation given by user mainly depends on user's experiences of using the services. Different users may have different opinions for the same service. Reputation is calculated as average of all user recommendation.

Parameter Weighting: Different user have different important of parameters. For example one user give first priority to response time and security then cost. So this type of weighting method help user to rank service according to their priority. In parameter weighting user give weight to nonfunctional parameter between different ranges. In [3] User gives weight between 0 and 1 . Web services are rank according to weight given by user.

\section{WEB SERVICE SELECTION AND RANKING APPROACHES}

In [1] Author proposes a Web service discovery architecture based on user's requirement of the various non-functional properties along with functional requirements and interaction with the system. Author proposes approach for developing and designing agent based architecture. Agent perform different task like Quality matching, feedback rating, service discovery. This architecture recommends service based on user functional and non-functional requirement.

In [2] Author proposed architecture which has specific broker for analysing service quality. This broker will assist user by analysing QoS of all web services in that functional domain. The broker use SOAPUI software for monitoring of web service quality. However in this paper user have no preference and they focus only web service load for retrieving service.

In [3] Author proposes a multi-level strategy for selection of optimal web services for Utility-Infrastructure providers. For Selection of optimal web service user's preference is compared with service quality. The offering that best matches the Quality of Service preference is taken to be the optimal one. This selection strategy also solves the problem of tie between services QoS score using weighting method. This method rank services base on weight given by user.

In [4] author proposes a trustworthy two-phase web service discovery mechanism based on QoS and collaborative filtering, web services are select using the relation between historical queries, web service and user. They also solve the problem of services with incorrect QoS information. However, there are also some problems exist in the recommender system, like sparsity, scalability and cold start problem.

In [5], Author introduces a QoS evaluation and monitoring mechanism with some new QoS parameters like Access Rate and Overall Aggregated Effective Quality of Service. The evaluation of proposed parameters is performed at the trusted third party broker's operating environment. Broker assigns 
rank by calculating value of OAEQoS parameter. With the help of parameters, the broker publishes the services with their overall quality score. However broker set the priority of the non-functional parameter for service recommendation so user has no preference for service selection.

In [6] author use particle swarm optimization technique for service selection. They used Service QoS information set which is composed of several QoS ternary constraint relations. Based on this relation they select services and rank service according to weight given by user.

In [7] web services are recommending based on user credibility. First, searching for recommended user from the credible user group, they separate user in two group, new user and old user (recommended user). After that Author use credible user recommendation calculation for service selection. Then QoS parameter latency, availability, price, security in QoS computation and service are rank using user preference. However service selection method is more complex and service selection is depending on user credibility which could be untrusted.

In [8] author provide model for web service selection. He introduce web service negotiator to verify the QoS information published by the publisher. This negotiator help user to find web service. A stability analyser has been used to assign the stability score to the web service if it consistently provides a good service otherwise assign a low stability score to that web service. The web services are ranking using the AHP and TOPSIS. The highest ranked web services then given to the user to fulfil his requirements.

Following table shows comparative study of different service selection and ranking method.

\begin{tabular}{|c|c|c|c|c|}
\hline Author & $\begin{array}{l}\text { Search } \\
\text { Method }\end{array}$ & $\begin{array}{l}\text { User } \\
\text { prefere } \\
\text { nce }\end{array}$ & $\begin{array}{l}\text { QoS } \\
\text { Parameter }\end{array}$ & $\begin{array}{l}\text { Service } \\
\text { Ranking }\end{array}$ \\
\hline [2] & Keyword & No & $\begin{array}{l}\text { Performan } \\
\text { ce }\end{array}$ & $\begin{array}{l}\text { Load on } \\
\text { Web } \\
\text { service }\end{array}$ \\
\hline [4] & $\begin{array}{l}\text { Collaborati } \\
\text { ve filtering }\end{array}$ & Yes & $\begin{array}{l}\text { Reputation, } \\
\text { reliability, } \\
\text { response } \\
\text { time }\end{array}$ & $\begin{array}{l}\text { Base on } \\
\text { QoS } \\
\text { Weight }\end{array}$ \\
\hline [5] & Keyword & No & $\begin{array}{l}\text { Access } \\
\text { rate, } \\
\text { Bounce } \\
\text { access rate, } \\
\text { failure rate, } \\
\text { Reliability, } \\
\text { Availabilit } \\
\text { y, } \\
\text { OAEQoS }\end{array}$ & $\begin{array}{l}\text { Overall } \\
\text { QoS } \\
\text { Aggregati } \\
\text { on }\end{array}$ \\
\hline [6] & $\begin{array}{l}\text { Partical } \\
\text { swarm } \\
\text { optimizatio } \\
\text { n }\end{array}$ & Yes & $\begin{array}{l}\text { Response } \\
\text { time } \\
\text { Availabilit } \\
\text { y } \\
\text {,Connectio } \\
\text { n Time, } \\
\text { Cost }\end{array}$ & $\begin{array}{l}\text { Base on } \\
\text { QoS } \\
\text { Weight }\end{array}$ \\
\hline
\end{tabular}

\begin{tabular}{|l|l|l|l|l|}
\hline$[7]$ & $\begin{array}{l}\text { User } \\
\text { credibility }\end{array}$ & Yes & $\begin{array}{l}\text { User } \\
\text { credibility }\end{array}$ & $\begin{array}{l}\text { Base on } \\
\text { QoS } \\
\text { Weight }\end{array}$ \\
\hline$[8]$ & Keyword & Yes & $\begin{array}{l}\text { Cost, } \\
\text { Response } \\
\text { time, } \\
\text { Reliability, } \\
\text { Security }\end{array}$ & $\begin{array}{l}\text { Using } \\
\text { AHP And } \\
\text { TOPSIS } \\
\text { algorithm }\end{array}$ \\
& & & & \\
\hline
\end{tabular}

\section{CONCLUSION}

As the number of similar functionality web service increase, the service selection issue is become more important. QoS of web service is consider as the secondary approach for service selection. Service recommendation using QoS help user to select service with high quality.

For accurate value of parameter, continues monitoring of web service require. From our study we conclude that in recent year many QoS computation research work has been done but they are no consider different aspect of web service. This is directly affected to the accuracy of parameter value. So there is need of QoS computation method which considers all aspect like different for web service. For web service recommendation use of semantic matching method and QoS for ranking web service satisfy user requirement. Furthermore User demands web service with not only functionality based but also based on high quality. In this situation ranking procedure must recommend web service based on user preference. Ranking and service selection based on User preference mostly satisfy the user requirement.

\section{REFERENCES}

[1] Rajendran, T., Balasubramanie, P." Flexible and Intelligent Architecture for Quality-Based Web Service Discovery with an Agent-Based Approach" IEEE, INCOCCI, Dec-2010.

[2] Susila, S., Vadivel, S. Julka, A, "Broker Architecture for Web Service Selection Using SOAPUI "IEEE dec-2012 Cloud Computing Technologies, pages (219-222).

[3] A.O Akingbesote, M.O Adigun, J.B Oladosu and E. Jembere."A Quality of Service Aware Multi-Level Strategy for Selection of Optimal Web Service".IEEE Adaptive Science and Technology, Page(s):1 - 5.

[4] Filtering.Szu-Yin Lin, Chin-Hui Lai, Chih-Heng Wu, Chi-Chun Lo "A Trustworthy QoS-based Mechanism for Web Service Discovery Based on Collaborative filtering".2013-IEEE.

[5] Maya Rathore, Ugrasen Suman "Evaluating QoS Parameters for Ranking Web Service" Advance Computing Conference (IACC), IEEE, Feb-2012, Page(s): 1437 - 1442 .

[6] J.Gobinath, D.Revathi "Performance View of Knowledge Based Quality of Web Service" Volume 3, Issue 4, April 2013. Ijarcsse.

[7] Yuehui Cui, Chang Chen, Zhengde Zhao "Web Service Selection Based on Credible User Recommended and QoS" Computer and Information Science (ICIS), 2012 IEEE/ACIS. May-30. 
[8] Negi, N., Chandra, S. "Web service selection on the basis of QoS parameter".IEEE, Contemporary Computing, Aug-2014, Page(s):495 - 500.

[9] Service-Oriented Architecture and Design Strategies by Mike Rosen Boris Lublin sky Kevin T. Smith.
[10] Kuyoro Shade O., Awodele O. Akinde Ronke O. and Okolie Samuel O. "QoS issues in web service"IJCSNS International Journal of Computer Science and Network S 94, VOL.12 No.1, January 2012 